Збірник наукових праць Українського державного університету залізничного транспорту

УДК 621.81

РОЗРАХУНКОВО-ЕКСПЕРИМЕНТАЛЬНЕ ВИЗНАЧЕННЯ ЙМОВІРНОСТЕЙ ПОЯВИ РІЗНИХ ЗА ВЕЛИЧИНОЮ ЗНОСІВ ТЯГОВИХ ЗУБЧАТИХ ПЕРЕДАЧ ЕЛЕКТРОПОїЗДІВ

Канд. техн. наук В. С. Тіщенко, асп. В. І. Громов, старш. викл. М. М. Одєгов

РАСЧЕТНО-ЭКСПЕРИМЕНТАЛЬНОЕ ОПРЕДЕЛЕНИЕ ВЕРОЯТНОСТЕЙ

ПОЯВЛЕНИЯ РАЗНЫХ ПО ВЕЛИЧИНЕ ИЗНОСОВ ТЯГОВЫХ ЗУБЧАТЫХ ПЕРЕДАЧ

Канд. техн. наук В. С. Тищенко, асп. В. И. Громов, старш. преп. Н. Н. Одегов

\title{
CALCULATION-EXPERIMENTAL DETERMINATION OF THE PROBABILITIES OF APPEARANCE OF DIFFERENT IN MAGNITUDE WEAR OF TRACTION GEARS.
}

Phd. tehn. V. Tishchenko, sciences, pg. V. Gromov, senior lecturer M. Odegov

DOI: https://doi.org/10.18664/1994-7852.176.2018.131254

Розглянуто особливості проведення статистичного аналізу результатів обміру зубів тягових зубчатих передач електропоїздів. Сформовані відповідні матриці, елементами яких $\epsilon$ ймовірності появи зносів, відповідні до них математичні сподівання, а також загальна дисперсія. Побудовано гістограми $і$ відповідні закони розподілу ймовірностей виникнення того чи іншого зносу. Розглянуто перспективи використання отриманих результатів при прогнозуванні залишкового ресурсу.

Ключові слова: зубчата передача, знос, розподілення ймовірностей.

Рассмотрень особенности проведения статистического анализа результатов обмера зубьев тяговых зубчатых передач электропоездов. Сформированы соответствующие матрицы, элементами которых являются вероятности появления износов, соответствуюшие им математические ожидания, а также общая дисперсия. Построень гистограммы и соответствующие законы распределения вероятностей возникновения того 
или иного износа. Рассмотрены перспективы использования полученных результатов при прогнозировании остаточного ресурса.

Ключевые слова: зубчатая передача, износ, распределение вероятностей.

The importance of studies aimed at assessing the residual resource of the components and components of the mechanical system of the rolling stock operated on the Ukrainian railways is substantiated. As the basic unit of the rolling stock involved in the suburban transportation of passengers, electric trains are allocated. The importance for the mechanical system of motor-car rolling stock traction gears was noted. The necessity of determining the laws of distribution of the main characteristics of the traction gear operation is substantiated. The expediency of considering the value of tooth wear along the dividing circle as one of the main characteristics of the gear drive operation was noted. Features of the statistical analysis of the results of measuring the gear teeth and the wheels of traction gears of ER2, ER2P and ER2T electric trains operating on the southern railway during a three-year period of operation (2015-2017) are considered. The tooth thickness values for dividing chords are presented in the summary table in the form of arrays for gears and gears with the corresponding value and series of rolling stock, the date of measurement. Based on the results of statistical processing of these arrays, corresponding matrices are formed, the elements of which are the probabilities of occurrence of different wear, the corresponding mathematical expectations and the general variance. Using the obtained matrices for the traction gears of the series of electric trains studied, histograms and corresponding laws were constructed to distribute the probabilities of occurrence of a particular wear. It is noted that during the analysis of the obtained diagrams, laws were obtained which correspond to the steady-state regime on the wear curve and do not exceed the allowable or reject dimensions. Prospects for using the results obtained in predicting the residual service life of traction gears of tractive rolling stock are considered.

Keywords: gearing, wear, probability distribution.

Вступ. Мережею залізниць України задовольняється значна частка вантажних та пасажирських перевезень. Велика частина їх припадає на приміські пасажирські перевезення, що здійснюються за допомогою моторвагонного рухомого складу (МВРС). Поряд 3 цим, якість перевезень значною мірою залежить від технічного стану парку МВРС, що експлуатується. Зважаючи на низькі темпи оновлення і те, що переважну більшість рухомого складу, задіяного в приміських перевезеннях, складають електропоїзди, які експлуатуються в понаднормовий термін, актуальним є питання підтримки наявного рухомого складу в працездатному стані та оцінки залишкового ресурсу окремих вузлів та систем існуючого МВРС [1].

Переважний обсяг приміських пасажирських перевезень на мережі залізниць України постійного струму здійснюється електропоїздами серій ЕР-2, ЕР-2P та ЕР-2Т, у механічній системі яких одним із найвідповідальніших можна виділити вузол тягового привода. Тяговий привод, у свою чергу, зручно розглядати у вигляді ряду послідовно з'єднаних модулів $[2,3]$, одним 3 яких $\epsilon$ тягова зубчата передача (ТЗП), що працює в режимах, пов'язаних 3 великими навантаженнями та зносами. Це обгрунтовує доцільність досліджень, спрямованих на оцінку залишкового ресурсу ТЗП існуючого парку MBPC.

Аналіз останніх результатів досліджень. Аналіз сучасних методів i підходів до проведення науково-дослідних та дослідно-конструкторських робіт показав, що прогнозування ресурсу масових об'єктів, до яких належить тягова зубчата передача, виконується 3 використанням методів, які базуються на 
використанні щільності розподілення ймовірності показників роботи об’єкта контролю. Поряд із цим, питання щодо оцінки існуючого стану ТЗП з точки зору прогнозування їх ресурсу та необхідний для цього математичний опис недостатньо висвітлені в сучасній літературі [4].

Визначення мети та завдання дослідження. Метою статті є висвітлення результатів розрахунково-експериментального визначення ймовірностей появи різних за величиною зносів тягових зубчатих передач електропоїздів ЕР-2, ЕР-2Р та ЕР-2Т.

Завданнями дослідження $є$ :

- обробка і аналіз зібраних статистичних даних обмірів зубів шестерень i коліс досліджуваних ТЗП;

- визначення статистичних показників оброблених масивів, а також визначення характеру закону розподілення зносів зубів тягової зубчатої передачі.

Основна частина дослідження. Відповідно до нормативної документації
[5] величина зносу визначалась як різниця товщин зубів за ділильними хордами нових шестерень та коліс і тих, що контролюються в експлуатації.

На першому етапі експериментальних досліджень були зібрані результати понад 1,5 тисячі обмірів товщин зубів шестерень та коліс за ділильною хордою упродовж чотирьох років (2014-2017 рр.) для електропоїздів, що експлуатуються на Південній залізниці. Їх аналіз i впорядкування дали змогу сформувати відповідні масиви, що зведені до таблиці. Особливістю дослідження $\epsilon$ аналіз ступенів зносу зубів, які відповідають ділянці сталого зносу відповідно до кривої Лоуренца [3]. Як приклад у табл. 1 наведено фрагмент зведеної таблиці масивів товщин зубів за ділильною хордою 3 вказаними датою вимірювання, номером шестірні й колеса та серією рухомого складу.

Таблиця 1

Фрагмент масиву результатів вимірювання

\begin{tabular}{|c|c|c|c|c|c|}
\hline $\begin{array}{c}\text { Дата } \\
\text { вимірювання }\end{array}$ & $\begin{array}{c}\text { Номер } \\
\text { шестірні }\end{array}$ & $\begin{array}{c}\text { Результат } \\
\text { вимірювання } \\
\text { шестірні }\end{array}$ & $\begin{array}{c}\text { Номер } \\
\text { колеса }\end{array}$ & $\begin{array}{c}\text { Результат } \\
\text { вимірювання } \\
\text { колеса }\end{array}$ & $\begin{array}{c}\text { Рухомий } \\
\text { склад }\end{array}$ \\
\hline- & - & - & - & - & - \\
\hline 15.11 .2017 & 61 & 17,6 & 74258 & 14,5 & ЕР-2Т \\
\hline 16.11 .2017 & 434 & 17,2 & 741373 & 14 & ЕР-2Р \\
\hline 17.11 .2017 & 018 & 17,3 & 74785 & 14,2 & ЕР-2Т \\
\hline- & - & - & - & - & - \\
\hline
\end{tabular}

За результатами аналізу масивів вимірювань були отримані закони розподілення ймовірності виникнення випадкової величини товщини зубів за ділильною хордою. Так, на рис. 1-4 наведено отримані закони розподілення ймовірності виникнення в процесі роботи ТЗП того чи іншого зносу. 


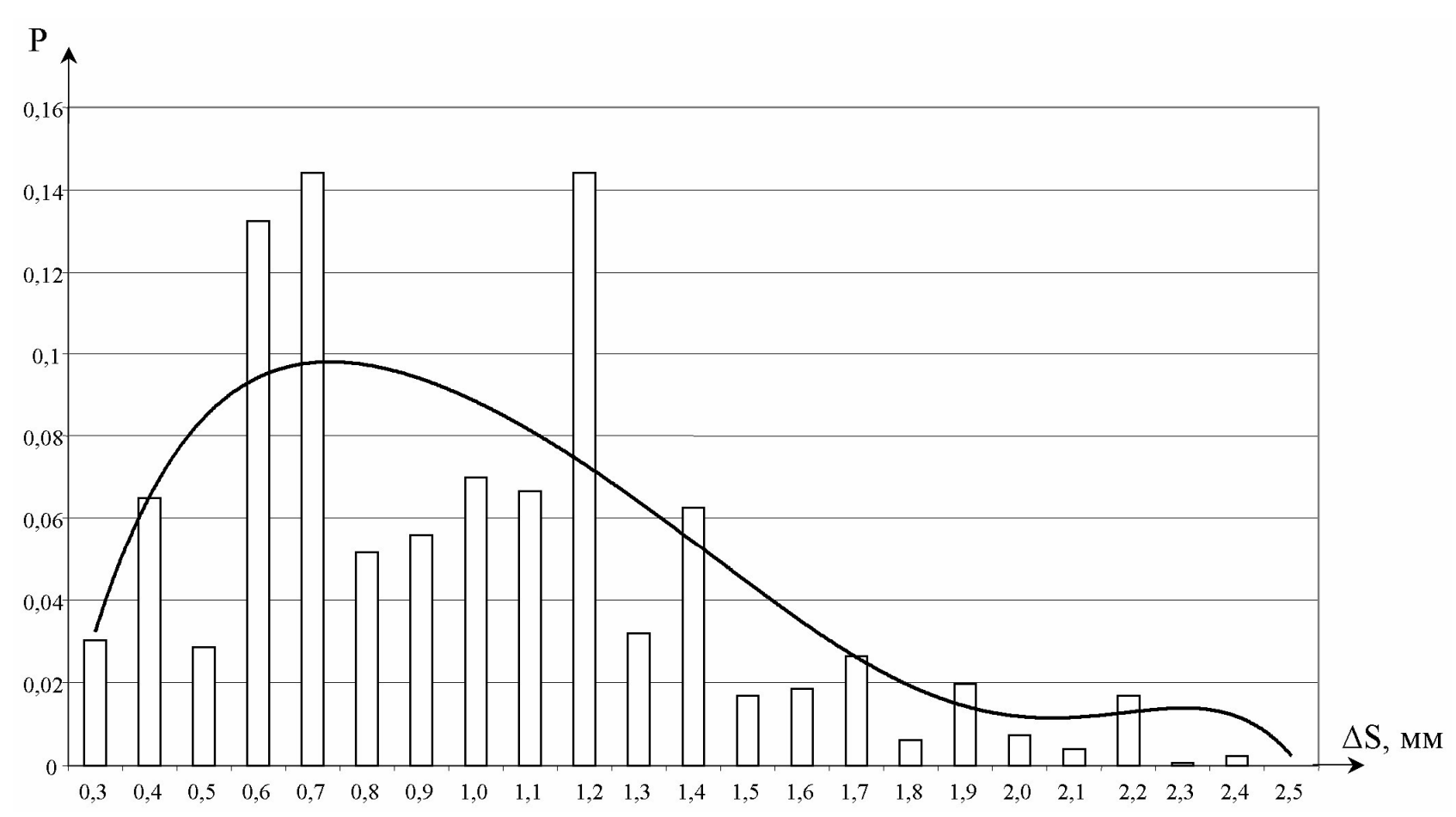

Рис. 1. Закон розподілення ймовірності виникнення зносів зубів шестірні електропоїзда ЕР-2

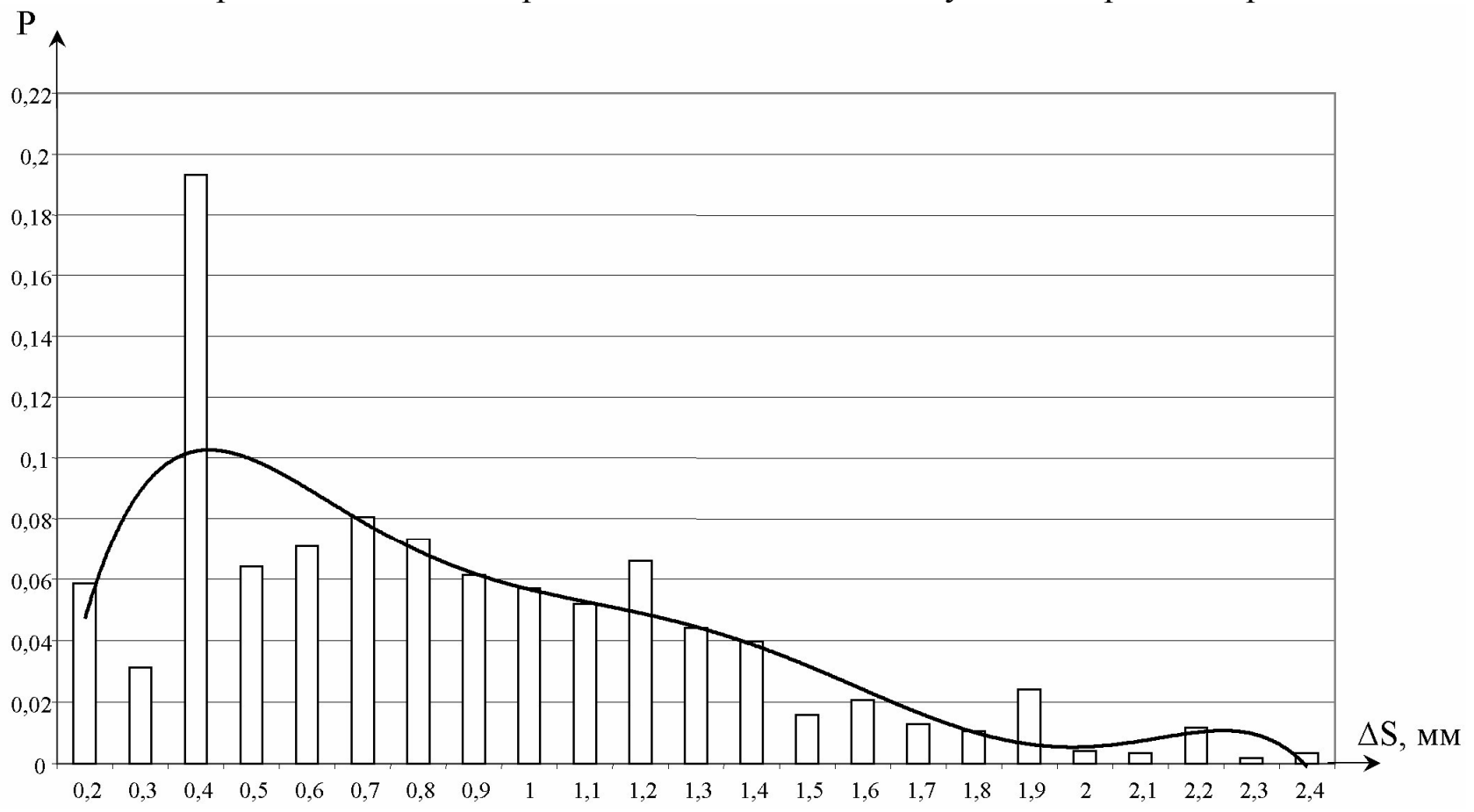

Рис. 2. Закон розподілення ймовірності виникнення зносів зубів зубчатого колеса електропоїзда ЕР-2 


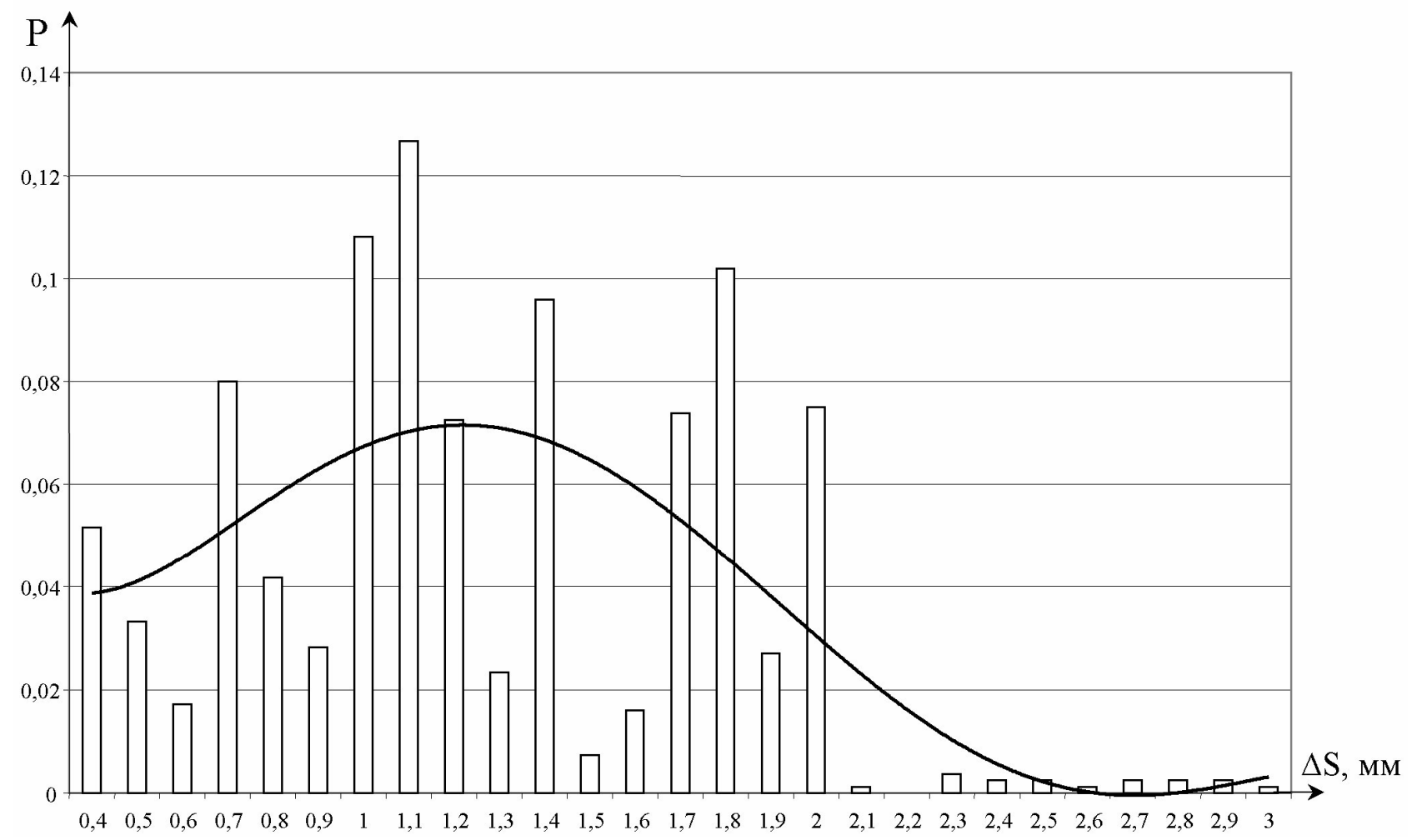

Рис. 3. Закон розподілення ймовірності виникнення зносів зубів шестірні електропоїздів ЕР-2Р та ЕР-2Т

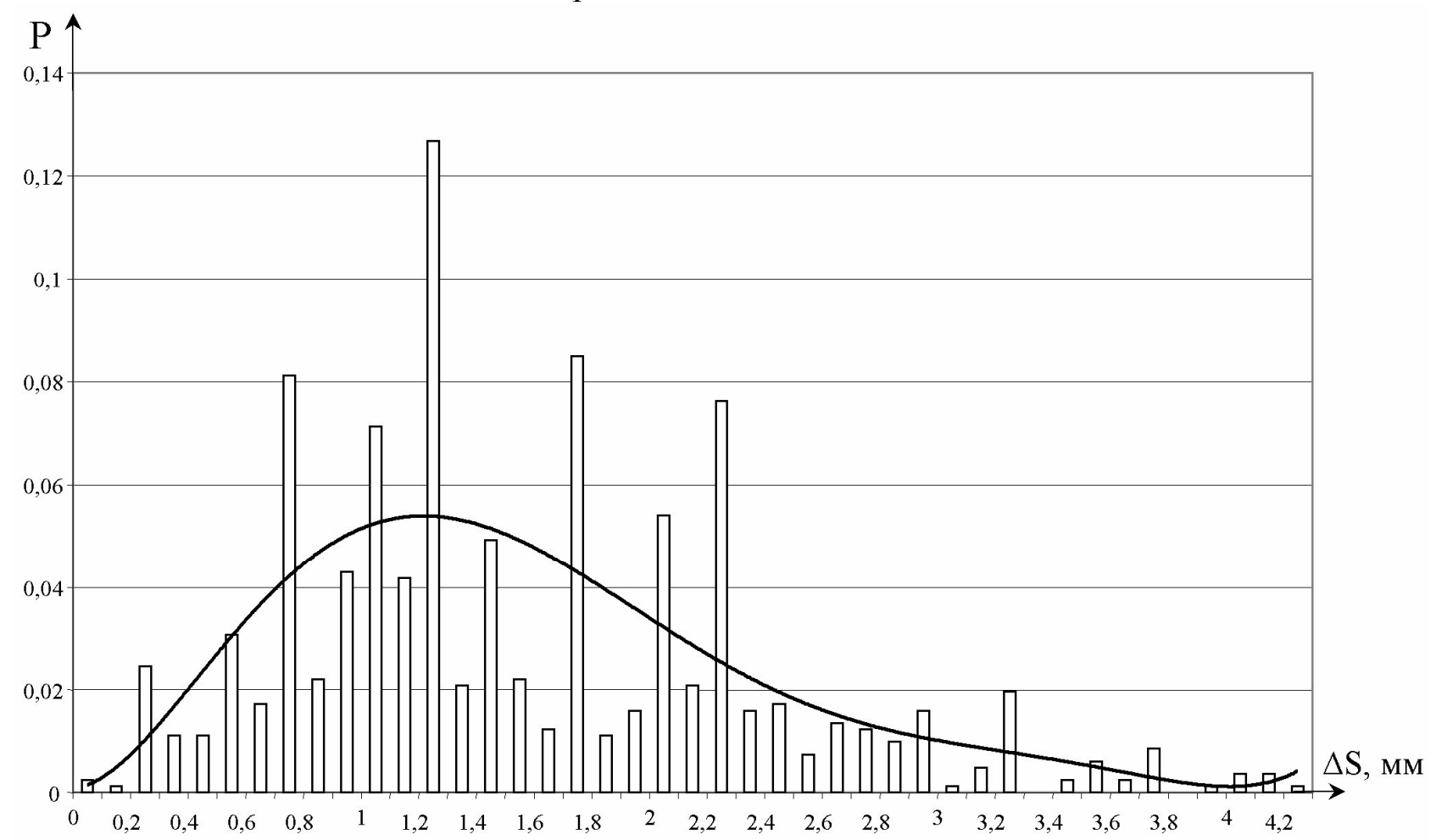

Рис. 4. Закон розподілення ймовірності виникнення зносів зубів зубчатого колеса електропоїздів ЕР-2Р та ЕР-2Т 
Оскільки тягові зубчаті передачі електропоїздів ЕР-2 мають конструктивні особливості в порівнянні із зубчатими передачами ЕР-2Р та ЕР-2Т, на наступному етапі було виявлено кількість розмірів, що збігаються для зубів шестерень та зубчатих коліс окремо для зазначеного тягового рухомого складу. Знаючи число однакових вимірювань, обчислено ймовірність їх виникнення, математичне сподівання та загальна дисперсія розсіювання. Наприклад, результати розрахунків для тягової зубчатої передачі електропоїзда ЕР-2 наведено у табл. 2.

Результати аналізу масивів вимірювань ТЗП ЕР-2

\begin{tabular}{|c|c|c|c|c|c|c|c|}
\hline \multicolumn{5}{|c|}{ Шестірня } & \multicolumn{4}{c|}{ Колесо } \\
\hline Розмір & $\begin{array}{c}\text { Число } \\
\text { вимі- } \\
\text { рювань }\end{array}$ & $\begin{array}{c}\text { Ймовір- } \\
\text { ність }\end{array}$ & $\begin{array}{c}\text { Матема- } \\
\text { тичне } \\
\text { сподівання }\end{array}$ & Розмір & $\begin{array}{c}\text { Число } \\
\text { вимі- } \\
\text { рювань }\end{array}$ & $\begin{array}{c}\text { Имовір- } \\
\text { ність }\end{array}$ & $\begin{array}{c}\text { Матема- } \\
\text { тичне } \\
\text { сподівання }\end{array}$ \\
\hline 1 & 2 & 3 & 4 & 5 & 6 & 7 & 8 \\
\hline 18,9 & 54 & 0,030168 & 0,570168 & 16 & 105 & 0,058659 & 0,938547 \\
\hline 18,8 & 116 & 0,064804 & 1,218324 & 15,9 & 56 & 0,031285 & 0,49743 \\
\hline 18,7 & 51 & 0,028492 & 0,532793 & 15,8 & 346 & 0,193296 & 3,054078 \\
\hline 18,6 & 237 & 0,132402 & 2,462682 & 15,7 & 115 & 0,064246 & 1,008659 \\
\hline 18,5 & 258 & 0,144134 & 2,66648 & 15,6 & 127 & 0,07095 & 1,106816 \\
\hline 18,4 & 92 & 0,051397 & 0,945698 & 15,5 & 144 & 0,080447 & 1,246927 \\
\hline 18,3 & 100 & 0,055866 & 1,022346 & 15,4 & 131 & 0,073184 & 1,127039 \\
\hline
\end{tabular}

Продовження табл. 2

\begin{tabular}{|c|c|c|c|c|c|c|c|}
\hline 1 & 2 & 3 & 4 & 5 & 6 & 7 & 8 \\
\hline 18,2 & 125 & 0,069832 & 1,27095 & 15,3 & 110 & 0,061453 & 0,940223 \\
\hline 18,1 & 119 & 0,06648 & 1,203296 & 15,2 & 102 & 0,056983 & 0,866145 \\
\hline 18 & 258 & 0,144134 & 2,594413 & 15,1 & 93 & 0,051955 & 0,784525 \\
\hline 17,9 & 57 & 0,031844 & 0,57 & 15 & 118 & 0,065922 & 0,988827 \\
\hline 17,8 & 112 & 0,06257 & 1,113743 & 14,9 & 79 & 0,044134 & 0,657598 \\
\hline 17,7 & 30 & 0,01676 & 0,296648 & 14,8 & 71 & 0,039665 & 0,587039 \\
\hline 17,6 & 33 & 0,018436 & 0,324469 & 14,7 & 28 & 0,015642 & 0,229944 \\
\hline 17,5 & 47 & 0,026257 & 0,459497 & 14,6 & 37 & 0,02067 & 0,301788 \\
\hline 17,4 & 11 & 0,006145 & 0,106927 & 14,5 & 23 & 0,012849 & 0,186313 \\
\hline 17,3 & 35 & 0,019553 & 0,338268 & 14,4 & 19 & 0,010615 & 0,152849 \\
\hline 17,2 & 13 & 0,007263 & 0,124916 & 14,3 & 43 & 0,024022 & 0,34352 \\
\hline 17,1 & 7 & 0,003911 & 0,066872 & 14,2 & 7 & 0,003911 & 0,055531 \\
\hline 17 & 30 & 0,01676 & 0,284916 & 14,1 & 6 & 0,003352 & 0,047263 \\
\hline 16,9 & 1 & 0,000559 & 0,009441 & 14 & 21 & 0,011732 & 0,164246 \\
\hline 16,8 & 4 & 0,002235 & 0,037542 & 13,9 & 3 & 0,001676 & 0,023296 \\
\hline 16,7 & 0 & 0 & 0 & 13,8 & 6 & 0,003352 & 0,046257 \\
\hline \multicolumn{4}{|c|}{ Дисперсія D=0,185917 } & \multicolumn{4}{|c|}{ Дисперсія D=0,228436 } \\
\hline
\end{tabular}

Видно, що розподіл розглянутих зносів відповідає ділянці сталих зносів, тобто не перевищує граничних значень, які складають для шестірні 3,4 мм, для колеса - 
5,3 мм, а найбільш вірогідні зноси відповідають 20-40\% від максимально допустимих. Наприклад, величина зносу (зменшення ділильної хорди) шестірні електропоїзда ЕР2 на рівні 0,7 мм виникне 3 ймовірністю 0,144 , математичне сподівання товщини зубця з таким зносом 2,67.
Висновки. Висвітлені в статті результати розрахунково-експериментального визначення ймовірностей появи різних за величиною зносів тягових зубчатих передач електропоїздів доцільно використовувати при прогнозуванні залишкового ресурсу шестерень та коліс тягових зубчатих передач електропоїздів, що експлуатуються [6].

\section{Список використаних джерел}

1. Державна цільова програма реформування залізничного транспорту на 20102019 роки. Міністерство інфраструктури [Текст] : затв. постановою Кабінету міністрів України № 1390 від 16 груд. 2009 р.

2. Мороз, В. І. Новий підхід до класифікації тягових приводів рухомого складу залізниць [Текст] / В. І. Мороз, О.В.Братченко, С.В.Бобрицький // Зб. наук. праць Донецького інституту залізничного транспорту. - Донецьк : ДонІЗТ, 2012. - Вип. 29. С. $162-166$.

3. Бабанін, О.Б. Прогнозування збільшення ресурсу тягових зубчатих передач електропоїздів за рахунок удосконалення технології ремонту [Текст] / О.Б. Бабанін, В. I. Громов // Зб. наук. праць Укр. держ. акад. залізнич. тансп. - Харків : УкрДАЗТ, 2014. Вип. 147. - С. 104-109.

4. ChengWang, Shou-renWang, Gao-qiWang. A method for calculating gear meshing efficiency by measured data from gear test machine [Text] // Measurement. - 2018. - Vol. 119. P. 97-101.

5. Правила технічного обслуговування та поточного ремонту електропоїздів i електросекцій [Текст] : ЦТ-0046. - К., 2005. - 320 с.

6. Болотин, В. В. Прогнозирование pecypca машин и конструкций [Текст]/ В. В. Болотин. - М. : Машиностроение, 1984. - 312 с.

\footnotetext{
Тіщенко Вадим Сергійович, канд. техн. наук, доцент кафедри механіки і проектування машин Українського державного університету залізничного транспорту. Тел.(057) 730-10-53. E-mail: mpmkafedra@ gmail.com. Громов Володимир Ігоревич, аспірант кафедри електроенергетики, електротехніки та електромеханіки Українського державного університету залізничного транспорту. Тел.(057) 730-10-53.

E-mail: eltech@kart.edu.ua.

Одєгов Микола Миколайович, старший викладач кафедри електроенергетики, електротехніки та електромеханіки Українського державного університету залізничного транспорту. Тел.(057) 730-19-96. E-mail: odegov@kart.edu.ua.
}

Тищенко Вадим Сергеевич, канд. техн. наук, доцент кафедры механики и проектирования машин Украинского государственного университета железнодорожного транспорта. Тел.(057) 730-10-53.

E-mail: mpmkafedra@gmail.com.

Громов Владимир Игоревич, аспирант кафедры электроэнергетики, электротехники и электромеханики Украинского государственного университета железнодорожного транспорта. Тел.(057) 730-10-53. E-mail: eltech@kart.edu.ua.

Одегов Николай Николаевич, старший преподаватель кафедры электроэнергетики, электротехники и электромеханики Украинского государственного университета железнодорожного транспорта.

Тел.(057) 730-19-96. E-mail: odegov@ kart.edu.ua. 
Tishchenko Vadim, PhD. Sc. Associate Professor, department mechanical engineers and designing the machines Ukrainian State University of Railway Transport. Tel.(057) 730-10-53. E-mail: mpmkafedra@ gmail.com. Gromov Vladimir, graduate student of department electric power engineering, electrical engineering and electromechanics State University of Railway Transport. Tel.(057) 730-10-53. E-mail: eltech@kart.edu.ua. Odegov Nikolay, Senior Lecturer of department electric power engineering, electrical engineering and electromechanics State University of Railway Transport. Tel.(057) 730-10-53. E-mail: odegov@kart.edu.ua.

Статтю прийнято 23.03.2018 p. 